\title{
Hemangiol in infantile haemangioma: A paediatric post- marketing surveillance drug study
}

\author{
Floriane Socchi $^{1}$ | Michele Bigorre ${ }^{2}$ | Marion Normandin ${ }^{3}$ | Guillaume Captier ${ }^{2}$ | \\ Didier Bessis $^{4}$ | Michel Mondain ${ }^{5}$ | Catherine Blanchet ${ }^{5}$ | Mohamed Akkari ${ }^{5}$ | \\ Pascal Amedro $^{1,6}$ | Arthur Gavotto ${ }^{1,6}$
}

${ }^{1}$ Department of Paediatric and Congenital Cardiology, M3C Regional Reference Centre, Clinical Investigation Centre, Montpellier University Hospital, Montpellier, France

${ }^{2}$ Department of Paediatric Plastic Surgery, Montpellier University Hospital, Montpellier, France

${ }^{3}$ Department of Clinical Pharmacy, Montpellier University Hospital, Montpellier, France

${ }^{4}$ Department of Dermatology, Montpellier University Hospital, Montpellier, France

${ }^{5}$ Department of Paediatric ENT, Head and Neck Surgery, Montpellier University Hospital, Montpellier, France

${ }^{6}$ PhyMedExp, INSERM, CNRS, University of Montpellier, Montpellier, France

\section{Correspondence}

Dr Arthur Gavotto, Department of Paediatric and Congenital Cardiology, M3C Regional Reference Centre, Montpellier University Hospital, 371 Avenue du Doyen Giraud, 34295, Montpellier, France.

Email: a-gavotto@chu-montpellier.fr
Aim: Infantile haemangioma $(\mathrm{IH})$ is the most common benign tumour in children. Since 2014, propranolol has become the first-choice therapy and currently Hemangiol is the only approved drug for complicated haemangioma. This postmarketing study reports the use of Hemangiol for $\mathrm{IH}$ in paediatric practice.

Method and Results: From January 2014 to November 2018, 94 children (median age 4 [0; 21] months; 75\% female) treated with Hemangiol for proliferative IH were enrolled in the study. The systematic paediatric cardiology consultation never contraindicated beta-blockers. Two Hemangiol initiation protocols were used: a conventional ambulatory 3-week titration phase protocol ( $n=76,80.9 \%$ ), and a rapid initiation protocol with a 48-hour dose escalation in conventional hospitalization for severe proliferative or ulcerated $\mathrm{IH}(\mathrm{n}=18,19.1 \%)$. In both protocols, the haemodynamic tolerance was good. The mean maintenance dose of Hemangiol was $2.7 \pm 0.8 \mathrm{mg} / \mathrm{kg} / \mathrm{day}$, with a median treatment duration of 7 [1.5; 19] months. Adverse events (AEs) have been found in 25 (26,6\%) patients, including 8 (8.5\%) patients with serious AEs (uncontrolled bronchial hyperreactivity, $n=5$; serious hypoglycaemia, $n=3$ ). Some patients had one or more AEs, a total of 24 nonserious AEs was reported in 19 patients (sleep disturbances, $n=9$; respiratory disorders, $\mathrm{n}=5$; digestive disorders, $\mathrm{n}=6$ ). No cardiac adverse event was reported.

Conclusion: This post-marketing surveillance drug study supports the good tolerance of Hemangiol in children with IH. A rapid initiation protocol is of interest when treatment is urgent. The pretherapeutic paediatric cardiology consultation should not be systematic but only indicated for specific patients.

ClinicalTrials.gov: NCT 04105517.

KEYWORDS

Hemangiol, infantile haemangioma, oral propranolol, safety

\section{1 | INTRODUCTION}

Originally classified in the vascular anomalies by Mulliken and Glowacki, ${ }^{1}$ infantile haemangioma $(\mathrm{IH})$ is the most common benign tumour in children. ${ }^{2,3} \mathrm{IH}$ belongs to the group of vascular tumours in 
the International Society for the Study of Vascular Anomalies (ISSVA) classification. ${ }^{4}$ Usually, IH will appear the first few days or weeks after birth. $^{5} \mathrm{IH}$ is characterized by its natural course being divided into three phases: a proliferative phase characterized by a rapid growth of the tumour (up to 4-12 months of life), a stabilization phase (from 12 to 36 months of life) and an involution phase marked by the regression of the lesion. ${ }^{6}$ This regression is complete in $90 \%$ of cases by the age of 4 , but without treatment we can observe up to $70 \%$ residual lesions, such as fibrofatty tissue, telangiectasia, skin laxity and scars. ${ }^{7}$ The proliferative phase may be marked by severe complications, such as necrosis, ulceration, bleeding or infection. Obstruction and functional impairment such as amblyopia, upper respiratory obstruction, obstruction of the nostrils or auditory channel, sphincter dysfunction or feeding disorders can be caused by periorificial locations of $\mathrm{IH}$ (eg, perioral and periorbital skin). Moreover, the aesthetic impact is not trivial, especially when IHs located in the centrofacial area are a source of disfigurement. ${ }^{8,9}$ Large segmental facial IHs may be part of the PHACES syndrome (posterior fossa anomalies, haemangioma, arterial lesions, cardiac abnormalities, eye anomalies, sternal defects) ${ }^{10,11}$ and segmental IHs of the lower body may be part of the LUMBAR syndrome (lower body haemangioma, urogenital, myelopathy, bony, anorectal and arterial, renal anomalies), ${ }^{12}$ also initially referred as PELVIS syndrome by our group. ${ }^{13}$ Finally, liver haemangioma and haemangiomatosis are high-risk complicated IHs as they may lead to cardiac failure. ${ }^{14}$

Initially, medical treatment of severe $\mathrm{IH}$ was based on systemic corticosteroid therapy. ${ }^{15,16}$ In 2008 , Leaute-Labreze et al fortuitously discovered the antiproliferative effect of propranolol when using this nonselective beta-blocker for a hypertrophic obstructive cardiomyopathy in a child with a facial $\mathrm{IH}$ treated by corticosteroids. ${ }^{17}$ The efficacy of oral propranolol in $\mathrm{IH}$ was demonstrated by two randomized controlled trials. $^{18,19}$ In 2014 the Pierre Fabre dermo-cosmetics laboratory (Paris, France) obtained European Medicines Agency (EMS) and US Food and Drug Administration marketing authorization for Hemangiol, the first and only drug currently approved for the treatment of proliferating $\mathrm{IH}$. Hemangiol is indicated to treat $\mathrm{IH}$ in children aged 5 weeks to 5 months in case of life or functional risk, painful ulcerated lesions or risk of permanent scarring or facial damage.

In this paediatric post-marketing surveillance drug study, we report the use of Hemangiol in our institution from 2014 to 2018.

\section{2 | METHODS}

\subsection{Study design and population}

This retrospective study was carried out from January 2014 to November 2018 in Montpellier University Hospital, France. In this tertiary care institution, all children with an $\mathrm{IH}$ requiring a medical treatment with a beta-blocker are systematically hospitalized for treatment initiation. In this study, the hospital discharge database PMSI (Programme de Medicalisation des Systemes d'Information) was used

\section{What is already known about this subject}

- Infantile haemangioma is the most common benign vascular tumour in children.

- Oral propranolol has become the first-choice therapy for complicated infantile haemangioma.

- Since 2014 Hemangiol has been the only approved drug.

\section{What this study adds}

- This postmarketing surveillance drug study supports the safety of Hemangiol and the importance of parental therapeutic education.

- This study supports the safety of a rapid initiation protocol when treatment is urgent.

- The pretherapeutic paediatric cardiology consultation should not be systematic but only indicated for selected at-risk patients.

for patient screening. The PMSI is a mandatory national database linked to the social security system, in which all hospitalizations are automatically and prospectively registered. This database uses a standardized diagnosis coding from the 10th revision of the International Classification of Diseases (ICD-10). The code associated with the term 'haemangioma' (D13) was used to screen patients and only children $<2$ years old treated with Hemangiol were included in the final analysis.

\subsection{Initiation and use of Hemangiol}

Hemangiol (ligand: propranolol) is a nonselective beta-adrenoceptor antagonist. $^{20}$ Immediately after the marketing authorisation published by the EMA in April 2014 (EU/1/14/919/001), our group of experts in proliferative $\mathrm{IH}$, involving plastic surgeons, dermatologists, ear nose and throat (ENT) physicians, and paediatric cardiologists, drafted a single and common institutional protocol on initiation and use of Hemangiol for $\mathrm{IH}$, adapted from the summary of product characteristics (SmPC). This protocol includes five consecutive stages:

1. The initial consultation with an expert in the diagnosis, treatment and management of $\mathrm{IH}$ (paediatric dermatologist, paediatric plastic surgeon, paediatric ENT physician or paediatric cardiologist) determined whether Hemangiol was indicated or not.

2. The paediatric cardiology consultation with clinical examination, electrocardiogram and echocardiography assessed the absence of contraindications for beta-blocker use: premature infants for whom the corrected age of 5 weeks has not been reached, 
breastfed infants in mothers treated with medicinal products contraindicated with propranolol, hypersensitivity to the active substance or to any of the excipients listed in section 6.1 of the SmPC, asthma or history of bronchospasm, second- or thirddegree atrioventricular blocks, disease of the sinus node (including sinoatrial block), bradycardia (heart rate $<100$ beats per minute (bpm) in infants 0-3 months old, $<90 \mathrm{bpm}$ in infants $3-6$ months old and $<80 \mathrm{bpm}$ in infants 6-12 months old), low blood pressure $(<65 / 45 \mathrm{mmHg}$ in infants $0-3$ months old, $<70 / 50 \mathrm{mmHg}$ in infants 3-6 months old, and $<80 / 55 \mathrm{mmHg}$ in infants 6-12 months old), cardiogenic shock, heart failure not controlled by treatment, severe peripheral arterial circulatory disturbances, infants prone to hypoglycaemia, and pheochromocytoma.

3. To initiate Hemangiol treatment, we defined a 'conventional' initiation protocol (as described in the SmPC) and a 'rapid' initiation protocol (defined by our group of experts, and not described in the SmPC).

- The conventional initiation protocol included a 3-week titration phase, as reported in the SmPC: starting dose of $1 \mathrm{mg} / \mathrm{kg} / \mathrm{day}$ (0.5 mg/kg b.i.d.) of propranolol base for 1 week, then $2 \mathrm{mg} / \mathrm{kg} /$ day $(1 \mathrm{mg} / \mathrm{kg}$ b.i.d.) for 1 week and finally $3 \mathrm{mg} / \mathrm{kg} /$ day $(1.5 \mathrm{mg} / \mathrm{kg}$ b.i.d.) as a maintenance therapeutic dose. During the titration phase, the child was hospitalised in our ambulatory paediatric daycare facility at day 1 (initiation), day 7 (week 1) and day 14 (week 2) with close clinical monitoring for 3 hours after treatment administration (hourly monitoring of vital constants and assessment of side effects). Bradycardia was defined as heart rate $<100 \mathrm{bpm}$ in infants 0-3 months old, <90 bpm in infants 3-6 months old and $<80 \mathrm{bpm}$ in infants 6-12 months old. Hypotension was defined as tension $<65 / 45 \mathrm{mmHg}$ in infants 0-3 months old, $<70 / 50 \mathrm{mmHg}$ in infants $3-6$ months old and $<80 / 55 \mathrm{mmHg}$ in infants 6-12 months old.

Parental education was provided by a specialist nurse, focusing on three key messages: (i) Hemangiol is to be given during or right after feeding to avoid the risk of hypoglycaemia, with one dose in the morning and one dose in late afternoon, respecting a time interval of at least 9 hours between the two intakes; (ii) if the child is not eating or is vomiting it is recommended that the dose should be skipped; (iii) if the child spits up a dose or does not take the entire medicinal product, no other dose should be given before the next scheduled dose. The information booklet provided by the pharmaceutical company (Pierre Fabre) was systematically given to parents, as well as our emergency paediatric cardiology 24/7 phone number.

- As urgent situations requiring propranolol initiation were not included in the original pharmaceutical drug trial, the SmPC only described the 3-week Hemangiol initiation protocol. Therefore, our group of $\mathrm{IH}$ experts designed a rapid initiation protocol dedicated to severe proliferative $\mathrm{IH}$ involving any vital risk or ulcerated $\mathrm{IH}$ with uncontrolled bleeding, pain or infectious risk. Such severe forms were managed in conventional hospitalisation in the paediatric cardiology unit using a rapid dose escalation scheme: Hemangiol initiation dose of $0.5 \mathrm{mg} / \mathrm{kg}$ (stage 1), then $1 \mathrm{mg} / \mathrm{kg} 12$ hours later (stage 2), then $1.5 \mathrm{mg} / \mathrm{kg} 12$ hours later (stage 3 ) to reach the maintenance therapeutic dose of $3 \mathrm{mg} / \mathrm{kg} /$ day in two daily intakes at day 2. Analgesics, local antibiotics and local skin care were provided when required upon IH specialist's recommendation. Continuous clinical monitoring was provided (hourly monitoring of vital constants, cardiac telemetry and assessment of side effects), as well as parental education (cf. previous section). In the absence of adverse effects or need for $\mathrm{IH}$ care, the patient was discharged after day 2 (rapid initiation protocol in Supporting Information Figure S1).

- The children underwent follow-up examination with the IH specialist 4-8 weeks after Hemangiol initiation in nonsevere $\mathrm{IH}$ and 1-2 weeks after Hemangiol initiation in severe cases. The IH specialist determined the frequency of the following consultations, as well as the overall treatment duration.

- The child underwent a paediatric cardiology consultation 3 months after Hemangiol initiation, or at any time if required by the $\mathrm{IH}$ specialist, the patient's family practitioner or after any family emergency phone call.

\section{3 | Outcome measures}

The data collection included the population and $\mathrm{IH}$ characteristics, and the indication of treatment during the initial consultation. Patient follow-up included treatment initiation until the end of treatment.

We collected all data from patient monitoring (cardiac examination, echocardiogram, ECG, cardiac monitoring) before, during (at each titration stage for both conventional and rapid protocols) and after Hemangiol initiation.

Parents of children under Hemangiol were asked to call the paediatric cardiology 24-hour hotline for any clinical symptom. No clinical events directly related to the disease were observed. Adverse events (AEs) and serious adverse events (SAEs) were collected, therefore we recorded all AEs, defined as any undesirable experience possibly associated with the use of Hemangiol from drug initiation and throughout the follow-up. SAEs were defined as life-threatening events or adverse events leading to death, hospitalisation, disability or permanent damage, intervention to prevent permanent impairment or any important medical event as defined by the drug agencies. SAEs were reported to pharmacovigilance and causality was established using the standard method derived from Bégaud et al. ${ }^{21}$ This algorithm is based on an intrinsic score, including chronological and semiological criteria ranging from 0 to 6 (from absence to strong relationship between drug and the occurrence of an $\mathrm{AE}$; scores $\geq 2$ indicate possible relation to treatment) and an extrinsic score based on bibliography. ${ }^{22}$

\section{$2.4 \quad$ Formal aspects}

The study was conducted in compliance with the Good Clinical Practices and Declaration of Helsinki principles. The study was approved 
by Montpellier University Hospital's institutional review board (2019_IRB-MTP_09-07). The study was registered on ClinicalTrials. gov (NCT 04105517).

\section{5 | Statistical analyses}

The study population was described using means and standard deviations (SD) for quantitative variables with normal distribution or medians and minimal/maximal values [min; max] otherwise. Frequencies and their associated percentages were used for qualitative variables. The normal distribution of continuous variables was explored graphically. Quantitative variables were compared using Student's ttest when the distribution was Gaussian or the Mann-Whitney test otherwise. For qualitative variables, groups were compared using the chi-squared test or Fisher's exact test. The statistical significance was set at 0.05 and analyses were performed using Excel software.

\subsection{Nomenclature of targets and ligands}

Key protein targets and ligands in this article are hyperlinked to corresponding entries in http://www.guidetopharmacology.org, the common portal for data from the IUPHAR/BPS Guide to PHARMACOLOGY.

\section{\begin{tabular}{l|l}
3 & RESULTS
\end{tabular}}

\section{1 | Population}

During the 5-year study period, 154 children < 2 years old were hospitalized in our institution with a main diagnosis of 'haemangioma' identified from the hospital PMSI database. From this cohort, 60 patients were not included in the study: 25 (16.2\%) cases were included in a concomitant randomised controlled trial comparing acebutolol versus propranolol in IH (NCT01743885), 17 (11\%) cases received no drug to treat their $\mathrm{HH}, 10(6.5 \%)$ cases had only surgical management, six (3.9\%) cases were treated with oral capsule of propranolol, and two (1.3\%) cases had significant missing data (lost to follow-up). In the group of patients not eligible for the study, children enrolled in the RCT or receiving oral capsule of propranolol had similar clinical characteristics as those receiving Hemangiol. Therefore, a total of 94 children (75\% female) with $\mathrm{IH}$ treated with Hemangiol were included in this study (Figure 1). All parents or legal guardians gave their informed consent.

The most common IH localisation was the head (59.6\%), especially the periocular $(n=23)$ and nasal $(n=11)$ regions. Rare cases of syndromic (PHACES syndrome, $n=2$; LUMBAR syndrome, $n=2$ ), hepatic haemangioma $(n=2)$ and miliary $\mathrm{IH}(n=1)$ were identified.

Hemangiol was initiated at a median age of 4 [0; 21] months, including two children $<5$ weeks and 29 children $>5$ months old. The main indication for $\mathrm{IH}$ treatment with Hemangiol was functional

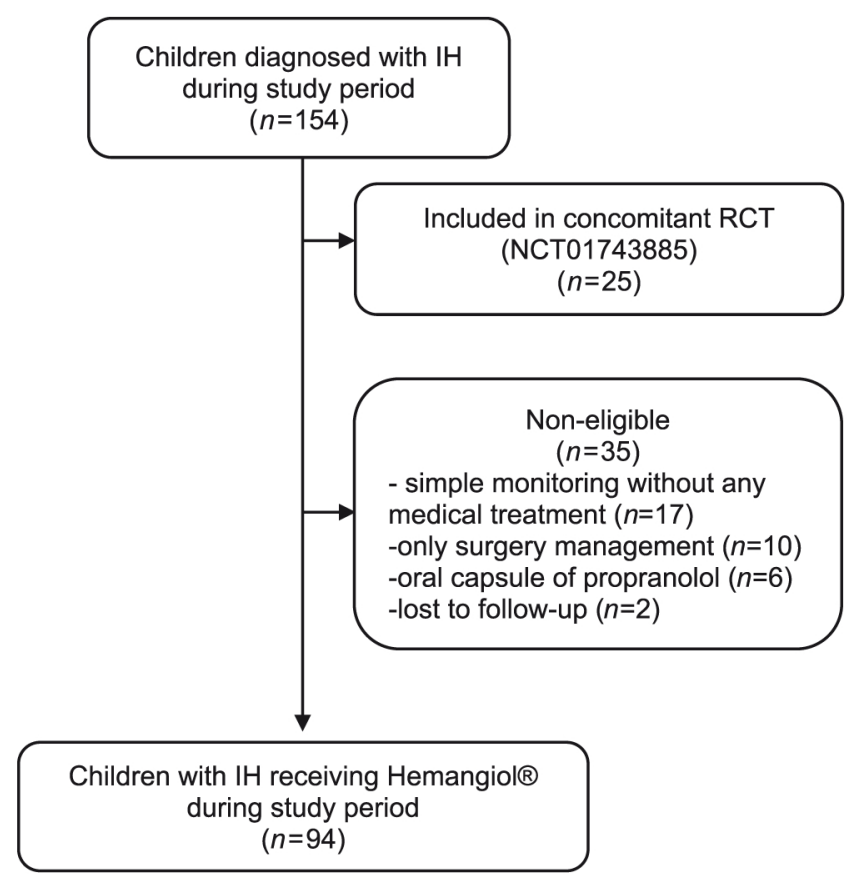

FIGURE 1 The flowchart showed the excluded children for this study. IH, infantile haemangioma; $\mathrm{RCT}$, randomized controlled trial

threat ( $n=36 ; 38.3 \%$ ) and mainly concerned facial IH, predominantly for periocular $(n=19)$ and nasal $(n=6)$ localisations. Ulcerated $\mathrm{IH}$ were treated with Hemangiol in 29 (30.9\%) children, especially in perineal localisations $(n=7)$. Life-threatening forms of $\mathrm{IH}$ required treatment with Hemangiol for five children (hepatic haemangioma, $n=2$; miliary, $n=1$; subglottic haemangioma, $n=2$ ). Patients' clinical characteristics were reported in Table 1.

\section{2 | Paediatric cardiology consultation}

The systematic paediatric cardiology consultation diagnosed a cardiac murmur in eight (8.5\%) subjects, of which four innocent murmurs and four congenital heart diseases: one case of minimal pulmonary valve stenosis, one case of coarctation of the aorta in a 4-month-old child with PHACES syndrome, one case of atrial septal defect and one case of ventricular septal defect. Systematic echocardiography reported increased cardiac output for the two subjects with hepatic haemangiomas and two cases of patent ductus arteriosus (PDA) in a neonate with $\mathrm{IH}$ and nonsustained ventricular tachycardia (spontaneous PDA closure), and in a 6-month-old infant born at 30 weeks gestation with PIK3CA mutation and subglottic haemangioma, who underwent percutaneous PDA closure.

The systematic echocardiography performed in the 86 remaining patients without any cardiac symptom or neonatal condition found 19 cases of nonsignificant cardiac features: patent foramen ovale ( $n=16$ ), moderate flow acceleration in the pulmonary artery branches ( $n=1$ ), small aorto-pulmonary collateral $(n=1)$ and trivial pulmonary regurgitation ( $n=1$ ). No further follow-up was indicated by the paediatric cardiologist in those 19 children. 
TABLE 1 Patient clinical presentation at Hemangiol initiation

\begin{tabular}{|c|c|c|}
\hline \multicolumn{2}{|l|}{ Patients included (n) } & \multirow{2}{*}{$\begin{array}{l}94 \\
70(74.5)\end{array}$} \\
\hline Gender & Girls & \\
\hline & Boys & $24(25.5)$ \\
\hline $\begin{array}{l}\text { Age (median [min; max]), } \\
\text { months }\end{array}$ & & $4[0 ; 21]$ \\
\hline $\begin{array}{l}\text { Height (median [min; } \\
\text { max]), cm }\end{array}$ & & $\begin{array}{l}63.8[45.5 ; \\
84]\end{array}$ \\
\hline $\begin{array}{l}\text { Weight (median [min; } \\
\text { max]), kg }\end{array}$ & & $6.5[3.6 ; 11]$ \\
\hline \multirow[t]{5}{*}{ Medical history } & None (n, \%) & $82(87.2)$ \\
\hline & Preterm birth (n, \%) & $5(5.3)$ \\
\hline & $\begin{array}{l}\text { Birth weight <2500 g } \\
\quad(\mathrm{n}, \%)\end{array}$ & $1(1.1)$ \\
\hline & $\begin{array}{l}\text { Congenital } \\
\text { abnormalities }\end{array}$ & $4(4.3)$ \\
\hline & Other & $2(2.1)$ \\
\hline \multirow[t]{3}{*}{ Type of IH } & Superficial (n, \%) & $35(37.2)$ \\
\hline & Deep (n, \%) & $8(8.5)$ \\
\hline & Mixt (n, \%) & $51(54.3)$ \\
\hline \multirow[t]{17}{*}{ Multifocal IH (n, \%) } & & $23(24.5)$ \\
\hline & Head (n, \%) & $56(59.6)$ \\
\hline & Periocular (n, \%) & $23(24.5)$ \\
\hline & Nose (n, \%) & $11(11.7)$ \\
\hline & Lips (n, \%) & $5(5.3)$ \\
\hline & Parotid (n, \%) & $5(5.3)$ \\
\hline & Other (n, \%) & $12(12.8)$ \\
\hline & Cervical (n, \%) & $5(5.3)$ \\
\hline & Cutaneous (n, \%) & $3(3.2)$ \\
\hline & Subglottic (n, \%) & $2(2.1)$ \\
\hline & $\begin{array}{l}\text { Thoracic and dorsal (n, } \\
\text { \%) }\end{array}$ & $12(12.8)$ \\
\hline & $\begin{array}{l}\text { Abdomen and pelvis } \\
\qquad(\mathrm{n}, \%)\end{array}$ & $12(12.8)$ \\
\hline & Hepatic (n, \%) & $2(2.1)$ \\
\hline & Perineal $(n, \%)$ & $7(7.4)$ \\
\hline & Other ( $n, \%)$ & $3(3.2)$ \\
\hline & Limbs (n, \%) & $8(8.5)$ \\
\hline & Miliary (n, \%) & $1(1.1)$ \\
\hline \multirow[t]{2}{*}{ Syndromic association } & $\begin{array}{l}\text { PHACES syndrome (n, } \\
\% \text { ) }\end{array}$ & $2(2.1)$ \\
\hline & $\begin{array}{l}\text { LUMBAR syndrome (n, } \\
\% \text { ) }\end{array}$ & $2(2.1)$ \\
\hline \multirow[t]{4}{*}{ Indication for treatment } & Functional (n, \%) & $36(38.3)$ \\
\hline & Ulceration (n, \%) & $29(30.9)$ \\
\hline & Aesthetic (n, \%) & $24(25.5)$ \\
\hline & Life threatening (n, \%) & $5(5.3)$ \\
\hline
\end{tabular}

Abbreviations: IH, infantile haemangioma; PHACES, posterior fossa anomalies, haemangioma, arterial lesions, cardiac abnormalities, eye anomalies and sternal defects; LUMBAR, lower body haemangioma, urogenital, myelopathy, bones, anorectal/arterial and renal anomalies.
The systematic ECG was normal in 93 (98.9\%) cases and diagnosed Wolff-Parkinson-White syndrome in one patient with no family history.

Overall, none of the findings observed during the paediatric cardiology consultation resulted in any contraindication for Hemangiol.

\subsection{Hemangiol initiation protocol}

The conventional Hemangiol initiation protocol was the most commonly used ( $\mathrm{n}=76 ; 80.9 \%$ ). The rapid Hemangiol initiation protocol concerned children with ulcerated $\mathrm{IH}(\mathrm{n}=11)$, life-threatening $\mathrm{IH}(\mathrm{n}=4)$, as well as the neonate with nonsustained ventricular tachycardia associated with $\mathrm{IH}$ of the cheek, the case of coarctation of aorta associated with $\mathrm{IH}$ of the arm and PHACES syndrome and a 2-month-old child with parotid $\mathrm{IH}$ with a risk of compression. In children with ulcerated $\mathrm{IH}$, the rapid Hemangiol protocol included the prescription of strong analgesics and local treatment during hospitalisation.

Hospital monitoring at the initiation of the treatment showed a significant decrease in heart rate 1 hour after treatment initiation, especially in stage 1 (from mean $140.3 \pm 18.1 \mathrm{bpm}$ to mean $127.1 \pm 16.1 \mathrm{bpm}, P<0.01)$. Then the heart rate remained stable during the monitoring. In stage 2, 1 hour after treatment increase, a less marked than in stage 1 but significant heart rate decrease was observed (from mean $128.1 \pm 19.0 \mathrm{bpm}$ to mean $121.7 \pm 17.0 \mathrm{bpm}$, $P=0.02$ ). No significant decrease in heart rate was observed in stage 3. Overall, no significant bradycardia was observed. We found a significant but nonsymptomatic decrease in diastolic blood pressure at stage 2 and stage 3, without requiring any drug discontinuation. No change was observed in the systolic blood pressure (Table 2).

We found no significant difference in terms of heart rate and blood pressure change between the two conventional and rapid initiation protocols.

\subsection{Follow-up of children under Hemangiol}

The maintenance therapeutic dose of Hemangiol was $2.7 \pm 0.8 \mathrm{mg} / \mathrm{kg} /$ day. The first follow-up consultation with an $\mathrm{IH}$ expert occurred at $1[0.5 ; 6]$ month, and the second one at $6[2 ; 13]$ months after Hemangiol initiation.

The first follow-up cardiology consultation occurred at $3[1 ; 7]$ months.

The median overall treatment duration was 7 [1.5; 19] months with a large majority of patients treated for 4 to 12 months $(n=60)$.

\section{5 | Adverse events}

No $A E$ was observed during the initiation of treatment in both conventional and rapid protocols. 
TAB LE 2 Patient cardiac monitoring during Hemangiol initiation

\begin{tabular}{|c|c|c|c|c|c|}
\hline \multirow[t]{2}{*}{ Dose } & \multirow[b]{2}{*}{ Cardiac monitoring } & \multicolumn{4}{|c|}{ Monitoring time } \\
\hline & & $\mathrm{HO}$ & $\mathrm{H} 1$ & $\mathrm{H} 2$ & H3 \\
\hline \multirow[t]{3}{*}{$0.5 \mathrm{mg} / \mathrm{kg}$} & $\mathrm{SBP}($ mean $\pm \mathrm{SD})$ & $94.8 \pm 12.5$ & $93.3 \pm 12.7$ & $90.8 \pm 14.4$ & $91.0 \pm 13.3$ \\
\hline & $\mathrm{DBP}($ mean $\pm \mathrm{SD})$ & $57.5 \pm 14.2$ & $54.8 \pm 13.4$ & $54.2 \pm 14.0$ & $53.7 \pm 12.7$ \\
\hline & $\mathrm{BPM}($ mean $\pm \mathrm{SD})$ & $140.3 \pm 18.1$ & $127.1 \pm 16.1^{*}$ & $129.3 \pm 15.0^{*}$ & $125.8 \pm 16.4^{*}$ \\
\hline \multirow[t]{3}{*}{$1 \mathrm{mg} / \mathrm{kg}$} & $\mathrm{SBP}($ mean $\pm \mathrm{SD})$ & $91.8 \pm 13.0$ & $90.8 \pm 15.2$ & $88.2 \pm 12.9$ & $91.0 \pm 12.2$ \\
\hline & $\mathrm{DBP}($ mean $\pm \mathrm{SD})$ & $59.7 \pm 15.6$ & $54.3 \pm 15.1^{*}$ & $48.9 \pm 14.3^{*}$ & $54.6 \pm 13.7^{*}$ \\
\hline & $\mathrm{BPM}($ mean $\pm \mathrm{SD})$ & $128.1 \pm 19.0^{* *}$ & $121.7 \pm 17.0^{*}$ & $119.6 \pm 15.7^{*}$ & $120.3 \pm 14.2^{+}$ \\
\hline \multirow[t]{3}{*}{$1.5 \mathrm{mg} / \mathrm{kg}$} & $\mathrm{SBP}($ mean $\pm \mathrm{SD})$ & $91.3 \pm 14.7$ & $88.9 \pm 15.3$ & $89.0 \pm 15.0$ & $90.7 \pm 12.2$ \\
\hline & $\mathrm{DBP}($ mean $\pm \mathrm{SD})$ & $58.1 \pm 13.5$ & $52.6 \pm 15.4^{*}$ & $51.7 \pm 13.6^{*}$ & $52.8 \pm 11.1^{*}$ \\
\hline & $\mathrm{BPM}($ mean $\pm \mathrm{SD})$ & $125.9 \pm 20.1^{* *}$ & $123.4 \pm 15.8$ & $120.7 \pm 14.8$ & $118.7 \pm 14.5^{*}$ \\
\hline
\end{tabular}

Abbreviations: HO, before Hemangiol initiation; H1, 1 hour after Hemangiol initiation; H2, 2 hours after Hemangiol initiation; $\mathrm{H} 33$ hours after Hemangiol initiation; SBP, systolic blood pressure; DBP, diastolic blood pressure; BPM, beats per minute (heart rate); SD, standard deviation.

${ }^{*}$ Significant statistical difference between $\mathrm{HO}$ and $\mathrm{H} 1$ or $\mathrm{H} 2$ or $\mathrm{H} 3$ during the same hospitalization $(P<0.05) .{ }^{* *}$ Significant statistical difference between $\mathrm{HO}$ at $0.5 \mathrm{mg} / \mathrm{kg}$ initiation and $\mathrm{HO}$ at $1 \mathrm{mg} / \mathrm{kg}$ or $1.5 \mathrm{mg} / \mathrm{kg}$ initiations $(P<0.05)$.

We did not find any significant change in the ECG before the initiation and 3 months after the initiation of Hemangiol with a PR interval at $115.3 \pm 17.6 \mathrm{~ms}$ vs $110.3 \pm 19.6 \mathrm{~ms}(P=0.1)$, QRS interval at $69.6 \pm 11.5 \mathrm{~ms}$ vs $68.8 \mathrm{~ms} \pm 12.1 \mathrm{~ms}(P=0.68)$, corrected QT interval at $378 \pm 20 \mathrm{~ms}$ vs $381 \pm 26 \mathrm{~ms}(P=0.37)$. No case of atrioventricular block or any other cardiac adverse event was reported.

During the follow-up, after the initiation period, 25 (26.6\%) patients experienced one or more adverse events. Among these patients, eight (8.5\%) children presented a SAE: five cases of uncontrolled bronchial hyperreactivity (one associated with pneumonia and diarrhoea) and three cases of serious hypoglycaemia. SAEs led to permanent treatment discontinuation in six cases, temporary discontinuation in one case and dose reduction in one case. For all SAEs, causality scores ranged from 2 to 5 out of 6 , suggesting possible to strong association between SAEs and propranolol (Table 3). As recommended by drug agencies, all cases of SAEs were reported to the national pharmacovigilance centre.

A total of 24 nonserious AEs were reported in 19 (20.2\%) patients (including two patients with SAEs and a nonserious $A E$, and five patients with two nonserious AEs): sleep disturbances $(n=9)$, primarily nightmares, respiratory disorders, especially acute bronchiolitis with temporally discontinuation of treatment ( $n=5$ ), and digestive disorders $(n=6)$ with benign diarrhoea, constipation, vomiting and anorexia. We also found one suspected case of hypoglycaemia, one case of asthenia, one skin rash and one case of repeated disabling sneezing. No nonserious $A E$ required hospitalization or prolonged drug discontinuation.

\section{4 | DISCUSSION}

This study investigated the current use of Hemangiol in 94 children with proliferating $\mathrm{IH}$. It provided new tolerance data on this treatment and the value of systematic cardiac screening before treatment. Moreover, the safety of a rapid initiation protocol was evaluated.

Overall, the population treated with Hemangiol in this study is similar to previous reports ${ }^{8}$ and our cohort is representative of the usually described population of $\mathrm{IH}$, with a predominant female representation. ${ }^{23}$ However, more subjects with preterm birth and low birth weight were present in our cohort, considering they were previously described as risk factors for $\mathrm{IH}^{2}{ }^{24}$ The cases with PHACES or LUMBAR syndromes included in the study underwent screening evaluation of clinical and radiological associated anomalies, as recommended in children with large segmental haemangiomas of the upper and lower body. ${ }^{10,12}$ The main indications for treatment of our cohort were $\mathrm{IH}$ with a functional threat, ulcerated haemangiomas and $\mathrm{IH}$ with an aesthetic prognosis, as recommended in the current guidelines. ${ }^{14}$ Children of our study were treated for an average of 7 months, which is moderately longer than in the initial trial (eg, 6 months). ${ }^{19}$ However, recent studies have suggested treatment for 6 to 12 months due to a greater $\mathrm{IH}$ rebound growth in shorter treatment duration. ${ }^{25,26}$ Indeed, treatment duration is mostly dependent on clinical complete lesion regression. ${ }^{27}$ Off-label use of Hemangiol was rare in this study. Two neonates $<5$ weeks of age were treated with a good tolerance during initiation and no reported adverse event during follow-up, which confirms a previous study on the safety of oral propranolol for $\mathrm{IH}$ in the neonatal period. ${ }^{28}$ Late Hemangiol initiations $>5$ months of age concerned 29 subjects in our study. Usually, late treatment initiations are related to a delayed referral to the specialist, especially for superficial $\mathrm{IH}^{29}$

The safety analysis found AEs in $26.6 \%$ patients, which is consistent with previous studies on oral propranolol, which reported AEs rates from $19.6 \%{ }^{30}$ to $38.2 \% .^{31}$ Sleep disturbances, wheezing and digestive side effects were the most frequently reported AEs in our cohort, as described in the previous studies, however peripheral coldness was not reported in our cohort. ${ }^{30,31}$ SAEs were found in $8.5 \%$ patients, exclusively severe hypoglycaemia and uncontrolled bronchial hyperreactivity, which is higher than previous reported SAEs rates, 


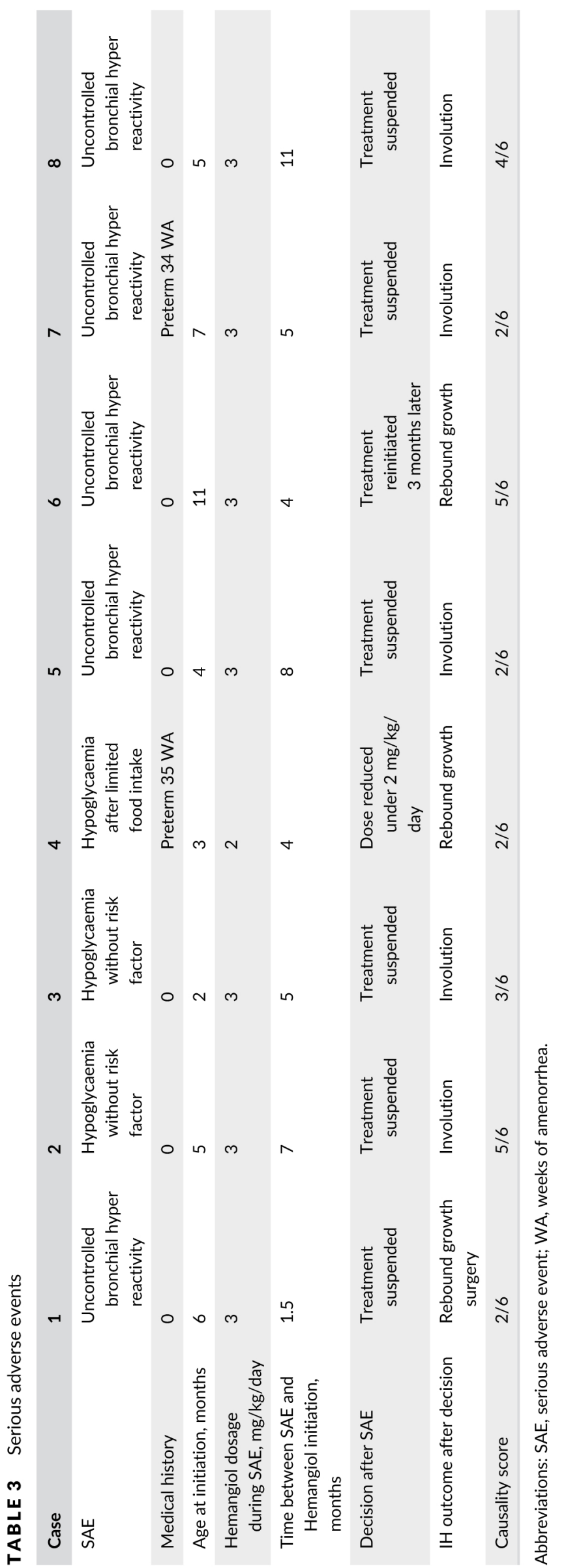


ranging from $2.6 \%{ }^{32}$ to $4.8 \% .{ }^{31}$ Cardiac SAEs, such as atrioventricular block, bradycardia and symptomatic hypotension, were not found in our cohort, as opposed to previous studies ${ }^{31,32}$ and despite a systematic paediatric cardiology pretherapeutic and follow-up assessment. Nevertheless, the causality of propranolol for cardiovascular SAEs in the literature remains unclear and suggests pre-existing conditions or incidental discovery. ${ }^{31,33}$ Of note, SAEs occurred in two prematurely born children, who may be more prone to hypoglycaemia and bronchial hyperreactivity as previously reported. ${ }^{34}$ Therefore, low dose of Hemangiol ( $2 \mathrm{mg} / \mathrm{kg} /$ day) could be of interest in such high-risk children, ${ }^{25,30}$ but the dosage of $3 \mathrm{mg} / \mathrm{kg} /$ day has been more investigated in pharmacokinetics and pharmacodynamics studies ${ }^{35,36}$ based on the manufacturer's clinical trial. ${ }^{19}$

For all SAEs, causality scores concluded to possible to strong relation to Hemangiol. As severe hypoglycaemia and uncontrolled bronchial hyperreactivity are well known SAEs, variability of causality scores came from intrinsic causation with variable chronological criteria (time to onset after taking the treatment, or evolution after lowering the dosage or stopping treatment) and the presence of confounding factors (ie, infectious for bronchospasms). As a result, SAEs with high causality scores (4 or 5 ) in our study were patients with complete description of the event, compatible time to onset, regression of $A E$ after stopping treatment and no confounding factor. Previous studies did not provide any details on the causality between such SAEs and treatment with Hemangiol.

From a general perceptive, those findings emphasize the importance of parental therapeutic education about these potential risks and how to manage them. During the treatment initiation period, oral information supported by an educational pack should be provided to parents in order to identify symptoms potentially related to SAEs. ${ }^{37}$ For example, parents should be fully aware that Hemangiol needs to be temporarily suspended in case of food intolerance or limited food intake in their child to avoid hypoglycaemia. ${ }^{38}$ Similarly, bronchial hyperreactivity reactions were

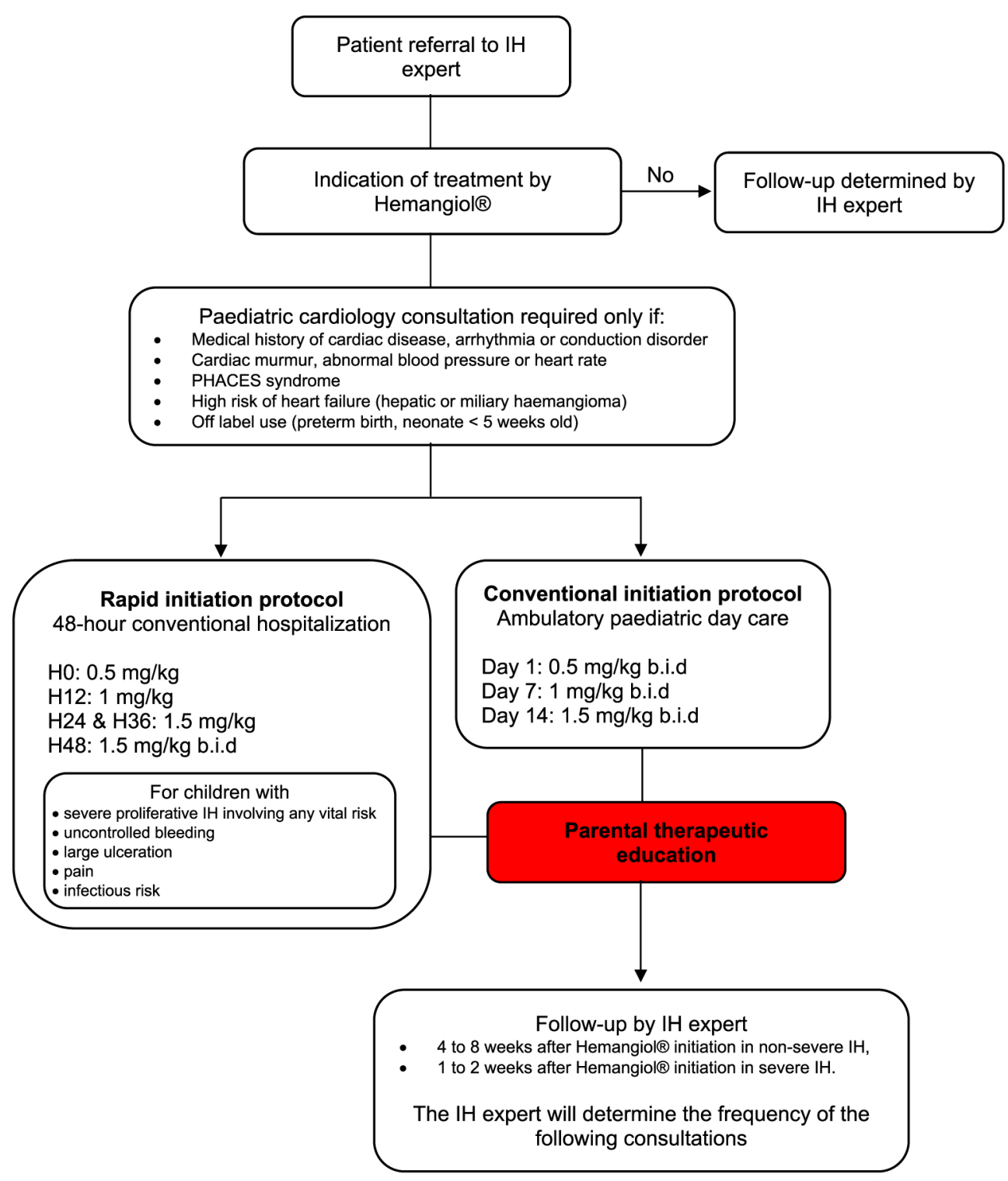

FIGURE 2 Steps for a safe

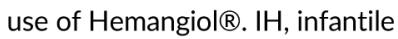
haemangioma; PHACES syndrome, posterior fossa anomalies, haemangioma, arterial lesions, cardiac abnormalities, eye anomalies and sternal defects 
often related to respiratory tract infections and therefore require appropriate parental supervision. ${ }^{31,39}$

Overall, the cardiac tolerance was good. No AE, serious or not, was reported during drug initiation at the hospital, whatever the protocol used, as well as during the follow-up. No significant decrease in systolic blood pressure was observed, and the initial decrease in heart rate and diastolic blood pressure was moderate and not clinically relevant, as in the literature. ${ }^{40-42}$ Similarly, previous studies have reported the safety of oral propranolol for the treatment of $\mathrm{IH}^{43}$ and suggested not extending cardiac monitoring beyond the initiation period except for heart rate during following consultations. ${ }^{44}$ In light of these results, an outpatient Hemangiol initiation protocol could be considered in selected and not at-risk patients, as suggested by Puttgen et al. ${ }^{45}$

This study supports the absence of relevance for a systematic pretherapeutic paediatric cardiology consultation. From a general perspective, cardiological tests are time-consuming and costly, and may cause a delay in the initiation of betablockers. Indeed, all cardiac findings observed in this cohort were mostly nonsignificant and did not result in any contraindication for betablockers. Therefore, a simple physical examination made by the IH expert seems sufficient to identify patients at risk for which a cardiological assessment would be necessary. Based on our cohort, children with $\mathrm{IH}$ requiring cardiological assessment are those with clinical symptoms (cardiac murmur), abnormal blood pressure or heart rate, syndromic forms (PHACES), high risk of heart failure (hepatic, miliary haemangiomas or very large superficial $\mathrm{IH}$ ) or off-label use (preterm birth, neonate period). These results are consistent with previous studies reporting that systematic echocardiography ${ }^{46,47}$ or $\mathrm{ECG}^{42,48}$ before propranolol initiation are not relevant in terms of contraindication assessment and correlation with SAE occurrence. ${ }^{49}$

Most patients (81\%) underwent a conventional initiation protocol with a 3-week titration phase in daycare hospital. This protocol seems safe and adapted to most children with $\mathrm{IH}$, as reported in costeffectiveness studies. ${ }^{50}$ Nevertheless, a 3-week delay to reach the maintenance dose of $3 \mathrm{mg} / \mathrm{kg} /$ day may not be appropriate in a therapeutic emergency situation, such as in $\mathrm{IH}$ involving any vital risk, bleeding, ulceration, pain or infectious risk. In our study, nearly $20 \%$ of patients with severe proliferative $\mathrm{IH}$ underwent a rapid initiation protocol, with a 48-hour dose escalation in conventional hospitalization in paediatric cardiology. This rapid protocol was well tolerated and facilitated the prescription of strong analgesics and local treatment, as in ulcerated $\mathrm{IH}$. In both conventional and rapid protocols, Hemangiol was well tolerated in terms of blood pressure and heart rate adaptation. We have drafted a diagram for safe use of Hemangiol, which is shown in Figure 2.

\subsection{Study limitation}

Despite the collection of AEs during patients' follow-up at the hospital, as well as through parent calls to the 24-hour hotline, the existence of missing data may be inherent to the retrospective design of the study. Moreover, 54 children with $\mathrm{IH}$ and treated with other forms of betablockers (acebutolol, propranolol) during the study period were not included in the analysis.

\section{5 | CONCLUSION}

In children treated with Hemangiol for proliferative $\mathrm{IH}$, this postmarketing surveillance drug study reported an $A E$ incidence rate of $26.6 \%$, of which $8.5 \%$ is nonfatal SAEs, supporting the importance of parental therapeutic education. The pretherapeutic paediatric cardiology consultation should not be systematic but only indicated on selected at-risk patients. In addition to the conventional initiation protocol with a 3-week titration phase in daycare hospital, the use of a rapid initiation protocol with a 48-hour dose escalation in conventional hospitalisation appears to address clinical management needs when treatment is urgent. Further evaluation in prospective studies is required to corroborate the effectiveness of this protocol in patients with severe proliferative $\mathrm{IH}$ involving any vital risk or ulcerated $\mathrm{IH}$ with uncontrolled bleeding, pain or infectious risk.

\section{ACKNOWLEDGEMENTS}

We thank our patients for their participation. This research did not receive any specific grant from any funding agency in the public, commercial or not-for-profit sector.

\section{COMPETING INTERESTS}

There are no competing interests to declare.

\section{CONTRIBUTORS}

Study concept and design: F.S., A.G. and P.A. Drafting of the manuscript: all. Critical revision of the manuscript for important intellectual content: all. Administrative, technical, or material support: P.A. Study supervision: A.G. and P.A.

\section{DATA AVAILABILITY STATEMENT}

The data that support the findings of this study are available from the corresponding author upon reasonable request.

\section{REFERENCES}

1. Mulliken JB, Glowacki J. Hemangiomas and vascular malformations in infants and children: a classification based on endothelial characteristics. Plast Reconstr Surg. 1982;69(3):412-420. https://doi.org/10. 1097/00006534-198203000-00002

2. Anderson KR, Schoch JJ, Lohse CM, Hand JL, Davis DM, Tollefson MM. Increasing incidence of infantile hemangiomas over the past 35-years: correlation with decreasing gestational age at birth and birth weight. J Am Acad Dermatol. 2016;74(1):120-126. https:// doi.org/10.1016/j.jaad.2015.08.024

3. Kilcline C, Frieden IJ. Infantile hemangiomas: how common are they? A systematic review of the medical literature. Pediatr Dermatol. 2008; 25(2):168-173. https://doi.org/10.1111/j.1525-1470.2008.00626.x 
4. Wassef M, Blei F, Adams D, et al. Vascular anomalies classification: recommendations from the International Society for the Study of vascular anomalies. Pediatrics. 2015;136(1):e203-e214. https://doi.org/ 10.1542/peds.2014-3673

5. Tollefson MM, Frieden IJ. Early growth of infantile hemangiomas: what parents' photographs tell us. Pediatrics. 2012;130(2):e314-e320. https://doi.org/10.1542/peds.2011-3683

6. Chang LC, Haggstrom AN, Drolet BA, et al. Growth characteristics of infantile hemangiomas: implications for management. Pediatrics. 2008;122(2):360-367. https://doi.org/10.1542/peds.2007-2767

7. Bauland CG, Lüning TH, Smit JM, Zeebregts CJ, Spauwen PHM. Untreated hemangiomas: growth pattern and residual lesions. Plast Reconstr Surg. 2011;127(4):1643-1648. https://doi.org/10.1097/PRS. Ob013e318208d2ac

8. Léauté-Labrèze $\mathrm{C}$, Harper Jl, Hoeger $\mathrm{PH}$. Infantile haemangioma. The Lancet. 2017;390(10089):85-94. https://doi.org/10.1016/S01406736(16)00645-0

9. Cheng CE, Friedlander SF. Infantile hemangiomas, complications and treatments. Semin Cutan Med Surg. 2016;35(3):108-116. https://doi. org/10.12788/j.sder.2016.050

10. Garzon MC, Epstein LG, Heyer GL, et al. PHACE syndrome: consensus-derived diagnosis and care recommendations. J Pediatr. 2016;178:24-33e2. https://doi.org/10.1016/j.jpeds.2016.07.054

11. Rotter A, Samorano LP, Rivitti-Machado MC, Oliveira ZNP, Gontijo B. PHACE syndrome: clinical manifestations, diagnostic criteria, and management. An Bras Dermatol. 2018;93(3):405-411. https://doi.org/ 10.1590/abd1806-4841.20187693

12. lacobas I, Burrows PE, Frieden IJ, et al. LUMBAR: association between cutaneous infantile hemangiomas of the lower body and regional congenital anomalies. J Pediatr. 2010;157(5):795-801e7. https://doi.org/10.1016/j.jpeds.2010.05.027

13. Girard C, Bigorre M, Guillot B, Bessis D. PELVIS syndrome. Arch Dermatol. 2006;142(7):884-888. https://doi.org/10.1001/archderm. 142.7.884

14. Krowchuk DP, Frieden IJ, Mancini AJ, et al. Clinical practice guideline for the management of infantile hemangiomas. Pediatrics. 2019;143 (1):1-28. https://doi.org/10.1542/peds.2018-3475

15. Bennett ML, Fleischer AB, Chamlin SL, Frieden IJ. Oral corticosteroid use is effective for cutaneous hemangiomas: an evidence-based evaluation. Arch Dermatol. 2001;137(9):1208-1213. https://doi.org/10. 1001/archderm.137.9.1208

16. Janmohamed SR, Madern GC, de Laat PCJ, Oranje AP. Educational paper: therapy of infantile haemangioma-history and current state (part II). Eur J Pediatr. 2015;174(2):259-266. https://doi.org/10.1007/ s00431-014-2404-5

17. Léauté-Labrèze $C$, De la Roque $E D$, Hubiche $T$, Boralevi $F$, Thambo JB, Taïeb A. Propranolol for severe hemangiomas of infancy. $N$ Engl J Med. 2008;358(24):2649-2651. https://doi.org/10.1056/ NEJMc0708819

18. Léauté-Labrèze $\mathrm{C}$, de la Roque $\mathrm{ED}$, Nacka $F$, et al. Double-blind randomized pilot trial evaluating the efficacy of oral propranolol on infantile haemangiomas in infants $<4$ months of age. $\mathrm{Br} J$ Dermatol. 2013;169(1):181-183. https://doi.org/10.1111/bjd.12217

19. Léauté-Labrèze $\mathrm{C}$, Hoeger $\mathrm{P}$, Mazereeuw-Hautier J, et al. A randomized, controlled trial of oral propranolol in infantile hemangioma. $\mathrm{N}$ Engl J Med. 2015;372(8):735-746. https://doi.org/10.1056/ NEJMoa1404710

20. Alexander SP, Christopoulos A, Davenport AP, et al. THE CONCISE GUIDE TO PHARMACOLOGY 2017/18: G protein-coupled receptors. Br J Pharmacol. 2017;174(Suppl 1):S17-S129. https://doi.org/10. 1111/bph.13878

21. Bégaud B, Evreux JC, Jouglard J, Lagier G. Imputation of the unexpected or toxic effects of drugs. Actualization of the method used in France. Therapie. 1985;40(2):111-118.
22. Arimone $\mathrm{Y}$, Bidault I, Dutertre J-P, et al. Réactualisation de la méthode française d'imputabilité des effets indésirables des médicaments. Therapie. 2011;66(6):517-525. https://doi.org/10.2515/ therapie/2011073

23. Haggstrom AN, Drolet BA, Baselga E, et al. Prospective study of infantile hemangiomas: demographic, prenatal, and perinatal characteristics. J Pediatr. 2007;150(3):291-294. https://doi.org/10.1016/j. jpeds.2006.12.003

24. Munden A, Butschek R, Tom WL, et al. Prospective study of infantile haemangiomas: incidence, clinical characteristics and association with placental anomalies. Br J Dermatol. 2014;170(4):907-913. https://doi. org/10.1111/bjd.12804

25. Yang H, Hu D-L, Shu Q, Guo X-D. Efficacy and adverse effects of oral propranolol in infantile hemangioma: a meta-analysis of comparative studies. World J Pediatr. 2019;15(6):546-558. https://doi.org/10. 1007/s12519-019-00285-9

26. Baselga E, Dembowska-Baginska B, Przewratil P, et al. Efficacy of propranolol between 6 and 12 months of age in high-risk infantile hemangioma. Pediatrics. 2018;142(3):e20173866. https://doi.org/10. 1542/peds.2017-3866

27. Chang L, Gu Y, Yu Z, et al. When to stop propranolol for infantile hemangioma. Sci Rep. 2017;7:43292. https://doi.org/10.1038/ srep43292

28. Ji Y, Chen S, Xiang B, Yang Y, Qiu L. Safety and tolerance of propranolol in neonates with severe infantile hemangiomas: a prospective study. Sci Rep. 2017;7(1):1-8. https://doi.org/10.1038/s41598-01701321-2

29. Onnis G, Dreyfus I, Mazereeuw-Hautier J. Factors associated with delayed referral for infantile hemangioma necessitating propranolol. J Eur Acad Dermatol Venereol JEADV. 2018;32(9):1584-1588. https:// doi.org/10.1111/jdv.14842

30. Wedgeworth E, Glover M, Irvine AD, et al. Propranolol in the treatment of infantile haemangiomas: lessons from the European propranolol in the treatment of complicated haemangiomas (PITCH) taskforce survey. Br J Dermatol. 2016;174(3):594-601. https://doi.org/10. 1111/bjd.14233

31. Leaute-Labreze C, Boccara O, Degrugillier-Chopinet C, et al. Safety of oral propranolol for the treatment of infantile hemangioma: a systematic review. Pediatrics. 2016;138(4):e20160353. https://doi.org/10. 1542/peds.2016-0353

32. Prey S, Voisard J-J, Delarue A, et al. Safety of propranolol therapy for severe infantile hemangioma. JAMA. 2016;315(4):413-415. https:// doi.org/10.1001/jama.2015.13969

33. Droitcourt C, Kerbrat S, Rault C, et al. Safety of oral propranolol for infantile hemangioma. Pediatrics. 2018;141(6):1-9. https://doi.org/10. 1542/peds.2017-3783

34. Ji Y, Chen S, Wang Q, et al. Intolerable side effects during propranolol therapy for infantile hemangioma: frequency, risk factors and management. Sci Rep. 2018;8(1):1-7. https://doi.org/10.1038/s41598018-22787-8

35. Frari LD, Léauté-Labrèze C, Guibaud L, et al. Propranolol pharmacokinetics in infants treated for infantile hemangiomas requiring systemic therapy: modeling and dosing regimen recommendations. Pharmacol Res Perspect. 2018;6(3):e00399. https://doi.org/10.1002/prp2.399

36. Takechi T, Kumokawa T, Kato R, Higuchi T, Kaneko T, leiri I. Population pharmacokinetics and pharmacodynamics of oral propranolol in pediatric patients with infantile hemangioma. J Clin Pharmacol. 2018; 58(10):1361-1370. https://doi.org/10.1002/jcph.1149

37. Martin K, Bleib F, Chamlin SL, et al. Propranolol treatment of infantile hemangiomas: anticipatory guidance for parents and caretakers. Pediatr Dermatol. 2013;30(1):155-159. https://doi.org/10.1111/pde. 12022

38. Holland KE, Frieden IJ, Frommelt PC, Mancini AJ, Wyatt D, Drolet BA. Hypoglycemia in children taking propranolol for the 
treatment of infantile hemangioma. Arch Dermatol. 2010;146(7):775778. https://doi.org/10.1001/archdermatol.2010.158

39. Shepherd D, Adams S, Wargon O, Jaffe A. Childhood wheeze while taking propranolol for treatment of infantile hemangiomas. Pediatr Pulmonol. 2012;47(7):713-715. https://doi.org/10.1002/ppul.21603

40. Petrovic J, Trifunovic B, Vukomanovic G, Topalovic M, Trajkovic G, Parezanović $\vee$. Oral propranolol for infantile hemangiomas: a prospective study on the role of 48-hour Holter monitoring in additional safety assessment. J Dermatol Treat. 2017;28(6):554-558. https://doi. org/10.1080/09546634.2016.1277177

41. Hengst $\mathrm{M}$, Oelert $\mathrm{M}$, Hoeger $\mathrm{PH}$. Blood pressure monitoring during the induction and maintenance period of propranolol therapy for complicated infantile hemangiomas: a prospective study of 109 infants. Pediatr Dermatol. 2015;32(6):802-807. https://doi.org/ 10.1111/pde.12681

42. Raphael MF, Breugem CC, Vlasveld FAE, et al. Is cardiovascular evaluation necessary prior to and during beta-blocker therapy for infantile hemangiomas? J Am Acad Dermatol. 2015;72(3):465-472. https://doi. org/10.1016/j.jaad.2014.12.019

43. Xu D-P, Cao R-Y, Xue L, Sun N-N, Tong S, Wang X-K. Treatment of severe infantile hemangiomas with propranolol: an evaluation of the efficacy and effects of cardiovascular parameters in 25 consecutive patients. J Oral Maxillofac Surg. 2015;73(3):430-436. https://doi.org/ 10.1016/j.joms.2014.09.010

44. Hoeger P, Harper J, Baselga E, et al. Treatment of infantile haemangiomas: recommendations of a European expert group. Eur J Pediatr. 2015;174(7):855-865. https://doi.org/10.1007/s00431-0152570-0

45. Puttgen KB, Summerer B, Schneider J, Cohen BA, Boss EF, Bauman NM. Cardiovascular and blood glucose parameters in infants during propranolol initiation for treatment of symptomatic infantile hemangiomas. Ann Otol Rhinol Laryngol. 2013;122(9):550-554. https://doi.org/10.1177/000348941312200903
46. Frongia G, Byeon J-O, Arnold R, Mehrabi A, Günther P. Cardiac diagnostics before oral propranolol therapy in infantile hemangioma: retrospective evaluation of 234 infants. World J Pediatr. 2018;14(3):254258. https://doi.org/10.1007/s12519-018-0137-7

47. Erdoğan I. Cardiac evaluation in children with hemangiomas. Turk Kardiyol Dernegi Arsivi-Arch Turk Soc Cardiol. 2016;44(6):498-502. https://doi.org/10.5543/tkda.2016.65171

48. Yarbrough KB, Tollefson MM, Krol AL, Leitenberger SL, Mann JA, MacArthur $\mathrm{CJ}$. Is routine electrocardiography necessary before initiation of propranolol for treatment of infantile hemangiomas? Pediatr Dermatol. 2016;33(6):615-620. https://doi.org/10.1111/pde.12972

49. Tang LY, Hing JW, Tang JY, et al. Predicting complications with pretreatment testing in infantile haemangioma treated with oral propranolol. Br J Ophthalmol. 2016;100(7):902-906. https://doi.org/10.1136/ bjophthalmol-2015-307284

50. Chaturvedi K, Steinberg JS, Snyder CS. Cost-effectiveness of treating infantile haemangioma with propranolol in an outpatient setting. Cardiol Young. 2018;28(10):1105-1108. https://doi.org/10.1017/ S1047951118000987 